\title{
Differential diagnosis of cystic lung diseases
}

\author{
Francesca Nosenzo \\ Irene Ariozzi \\ Nicola Sverzellati
}

Department of Radiology, University of Parma, Parma, Italy

\author{
Address for correspondence: \\ Nicola Sverzellati, MD \\ Department of Radiology \\ University of Parma \\ 43120 Parma, Italy \\ E-mail: nicola.sverzellati@unipr.it
}

\section{Summary}

A lung cyst is defined as a round parenchymal lucency or area of low attenuation with a thin wall. Although lymphangioleiomyomatosis (LAM) and Langerhans cell histiocytosis (LCH) are the most frequently encountered causes, the differential diagnosis for diseases characterised by diffuse lung cysts is broad ranging from isolated chest disorders to rare multisystem diseases. This article will illustrate and describe the spectrum of diseases associated with air cysts at high-resolution CT (HRCT), highlighting disorders in which the HRCT findings can be diagnostic.

KEY WORDS: lung cysts, HRCT, cystic lung disease, differential diagnosis.

\section{Introduction}

Pulmonary diseases characterised by diffuse cystic air spaces are uncommon disorders. The CT findings of these conditions (distribution, shape and ancillary sign) are sometimes quite characteristic and give clues for the specific diagnosis without further investigation. This article will illustrate and describe the spectrum of diffuse cystic lung diseases on HRCT, including rare entities and with particular attention to characteristic patterns of the cystic abnormalities. The pathological basis as well as the mechanisms leading to cyst formation in the various cystic lung diseases is also briefly described.

\author{
Multiple diffuse cysts: LAM, LCH
}

\section{LAM}

Lymphangioleiomyomatosis (LAM) is a rare disease in which an abnormal proliferation of smooth muscle cells in the pulmonary interstitium results in thickening of the walls of lymphatics and blood vessels and in a partially or completely occlusion of the lumina of bronchioles (1).

This condition is a multisystemic disease that can also involve the abdomen (usually with renal angiomyolipomas) and it may occur isolated or in association with tuberous sclerosis (2).

LAM disease occurs almost
The most useful sign in differentiating LAM from LCH is the distribution of cysts: in LAM the distribution of cysts is diffuse in the lung with involvement of the costophrenic recesses, whereas in LCH the costophrenic sulcis are typically spared. exclusively in women of childbearing age, from 20 to 35 years old; however, it also can present after menopause, particularly in women undergoing estrogen hormonal treatment (3).

Clinically, it presents most commonly with dyspnea or recurrent pneumothoraces, due to the rupture of subpleural cysts; the involvement of venous and lymphatic vessels by the LAM cells may lead respectively to pulmonary hemorrhage with haemoptysis, and chylothorax.

At high-resolution computed tomography (HRCT) imaging, LAM is characterized by diffusely distributed multiple pulmonary cysts that are likely the result of focal bronchiolar dilatation caused by a valve-like effect secondary to progressive airway obstruction. Cysts are not related to fibrosis and therefore they are surrounded by relatively normal lung parenchyma.

Cysts are numerous and distributed throughout all lung zones, without any upper or lower lobes predominance. They have regular round shape and a thin wall, and are almost of equal in size (generally a few millimeters) (Figure 1).

On HRCT, other associated abnormalities in LAM may include pneumothoraces, chylous pleural effusion and lymphonode enlargement.

Obviously, the sole HRCT features of LAM are diagnostic in the correct clinical context, especially when typical pulmonary cysts are associated with renal angiomyolipoma. In such case scenarios, no lung biopsy is required to confirm the diagnosis (4).

The differential diagnosis for LAM, based on CT imaging, especially includes Langerhans cell histiocytosis (LCH) and emphysema. 


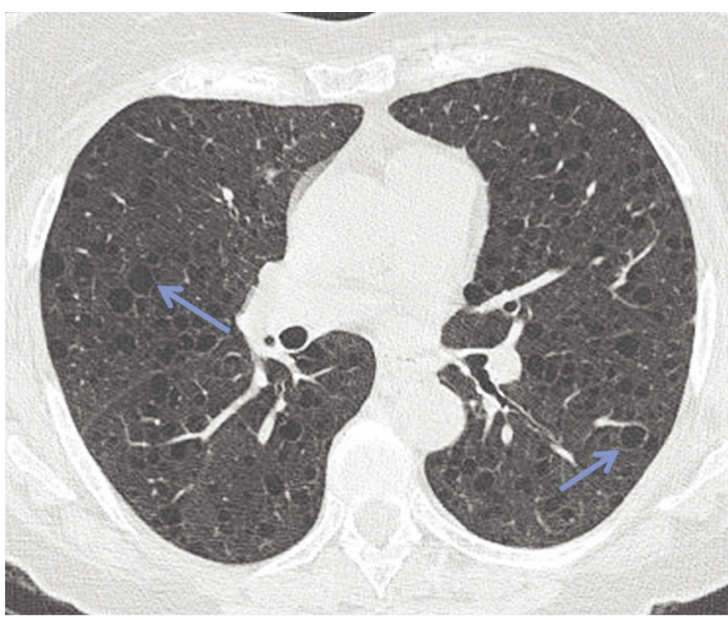

Figure 1 - LAM. High-resolution CT (HRCT) in a patient with LAM. The cysts are diffuse in distribution, thin-walled and regularly round (arrows).

The most useful sign in differentiating LAM from $\mathrm{LCH}$ is the distribution of cysts: in LAM the distribution of cysts is diffuse in the lung with involvement of the costophrenic recesses, whereas in $\mathrm{LCH}$ the costophrenic sulcis are typically spared. The cysts in LAM are typically thin walled and regularly round in shape, whereas in LCH cysts have usually a bizarre shape.

Lung nodules are usually absent in LAM (or, when present, they are single or scattered), whereas they are a classical feature in early $\mathrm{LCH}$.

Sometimes the most challenging differential diagnosis is between LAM and emphysema. However, identification of residual core lobular structures in the center of "cysts", typical of emphysema, may be helpful in differentiating these conditions.

\section{$\mathrm{LCH}$}

Langerhans cell histiocytosis ( $\mathrm{LCH})$ is an idiopathic disorder caused by a clonal proliferation of Langerhans cells that infilter the lung parenchyma and other organs. As reported by Lee at al. (5), in $60 \%$ of cases there is an isolated pulmonary disease, $20 \%$ of cases also have bone involvement and another $20 \%$ have

\begin{abstract}
In the differential diagnosis on HRCT between LCH and LAM and emphysema it is important to consider the upper lobe predominance distribution of the cysts in $\mathrm{LCH}$, with relative sparing of both lung bases, medial tips of the middle lobe and lingula and costophrenic recesses and the bizarre shape of the cysts.
\end{abstract}

\section{multivisceral disease.}

Langerhans cells are normally localized in epithelia, lymphonodes, thymic epithelium and bronchial epithelium, representing an immature form of dendritic cells with antigen presenting functions and characteristic cytoplasmic organelles known as Birbeck granules. Histologically, LCH is characterized by the proliferation of Langerhans cells and formation of granulomas within bronchioles, associated to an involvement

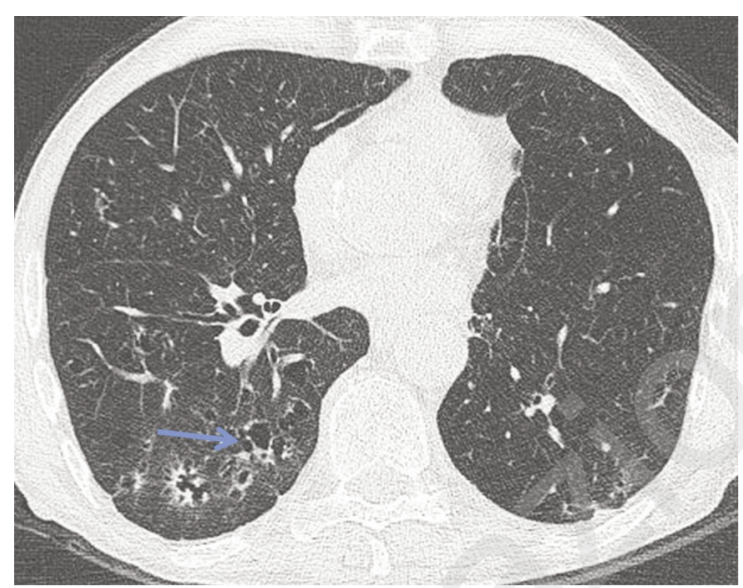

Figure 2 - LCH. High-resolution CT (HRCT) image shows bizarre cysts and cavitated nodules (arrow) in the upper lobes.

of the interstitium and pulmonary vasculature. $\mathrm{LCH}$ occurs almost exclusively in young patients, between the ages of 20 and 40 years, and in particular in which are current smokers (6).

Patients may be asymptomatic or present with dyspnea and cough; less frequently they report chest pain, fever and pneumothorax during the course of the disease.

A remission of disease can be achieved in the majority of patients especially in those that stop to smoke. The HRCT appearances of LCH are often characteristic and reflect the temporal phase of the disease. In the early stages, centrolobular nodules (which correspond with Langerhans cell granulomas) are the predominant features: nodules are multiple and they are usually $<5 \mathrm{~mm}$ in size.

The presence of cysts usually develop only during the later stages of the disease.

Cysts in LCH probably arise because of focal dilatation of bronchi caused by destruction of small airway bronchial walls due to Langerhans cell lesions and reflect Langerhans cell granuloma induced fibrosis rather than bronchial dilatation.

This process may start from non-cavitary nodules that progressively become thick-walled cavitary nodules and then thin-walled cysts, with a predominant presence of both thin- and thick-walled irregular cystic spaces.

The cysts are usually most profuse in the upper lobes, with relative sparing of the costophrenic recesses and the medial tips of the middle lobe and lingula; with increasing severity, the cysts may assume bizarre shapes mimicking bronchiectasis and are different sizes (from 1 to $3 \mathrm{~cm}$ ) (Figure 2).

The combination of nodules, cavitating nodules and cysts, localized in the upper lobes, in a young smoker is highly suggestive for $\mathrm{CT}$ diagnosis of $\mathrm{LCH}$; however, to identify the pathognomonic Birbeck granules at electron microscopy, for having a pathological confirmation of the diagnosis, bronchoalveolar lavage (BAL) may be 
usefull, with an high specificity and more safety than transbronchial lung biopsy (TBB) (7).

In the differential diagnosis on HRCT between LCH and LAM and emphysema it is important to consider the upper lobe predominance distribution of the cysts in $\mathrm{LCH}$, with relative sparing of both lung bases, medial tips of the middle lobe and lingula and costophrenic recesses and the bizarre shape of the cysts.

\section{Scattered cysts with ancillary CT signs: LIP, HP,DIP}

\section{LIP}

Lymphocytic interstitial pneumonia (LIP) is an uncommon, benign, lymphoproliferative disorder characterized by a diffuse and interstitial proliferation of small lymphocytes and plasmacells (8).

LIP is very rarely idiopathic condition, but is often associated with collagen vascular disorders (particularly Sjogren's syndrome), or AIDS. Less commonly, LIP is associated with autoimmune thyroid disease, Castleman's disease, myasthenia gravis, pernicious anemia and chronic active hepatitis $(9,10)$.

Histologically, LIP is characterized by nodular infiltrates of lymphoid cells with peribronchiolar distribution that develop to the cystic air space formation due to the partial airway obstruction (11).

LIP is more frequently seen in 50 years old and older

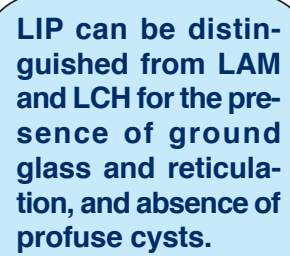
women. Symptoms are usually dyspnea or cough. The disease usually responds to treatment with corticosteroid, but it may be complicated by progressive pulmonary fibrosis or malignant lymphoproliferative disorders (12-14).

The predominant abnormalities on HRCT evaluation are as follows: patchy ground-glass opacity, lung cysts scattered, interlobular septal thickening, fine reticular opacities and lymphonodes enlargement (Figure 3).

Cysts are seen in about two-thirds of patients (15). They usually are thin walled, small (though larger up to $3 \mathrm{~cm}$ in size have been reported), and display a scattered distribution.

Surgical lung biopsy is required to confirm the clinicalradiological diagnosis of LIP, and in some cases to exclude low-grade lymphoma.

LIP can be distinguished from LAM and LCH for the presence of ground glass and reticulation, and absence of profuse cysts.

The cysts in LIP are more scattered than those observed in $\mathrm{LCH}$. In addition, upper lobes nodules are not a feature of LIP.

HP

Hypersensitivity pneumonitis (HP) is an immunologically mediated granulomatous inflammatory disease involving the lung parenchyma and terminal airways secondary to repeated exposure and inhalation of a variety of agents, ranging from organic particles to chemotherapy agents, in a sensitized host.

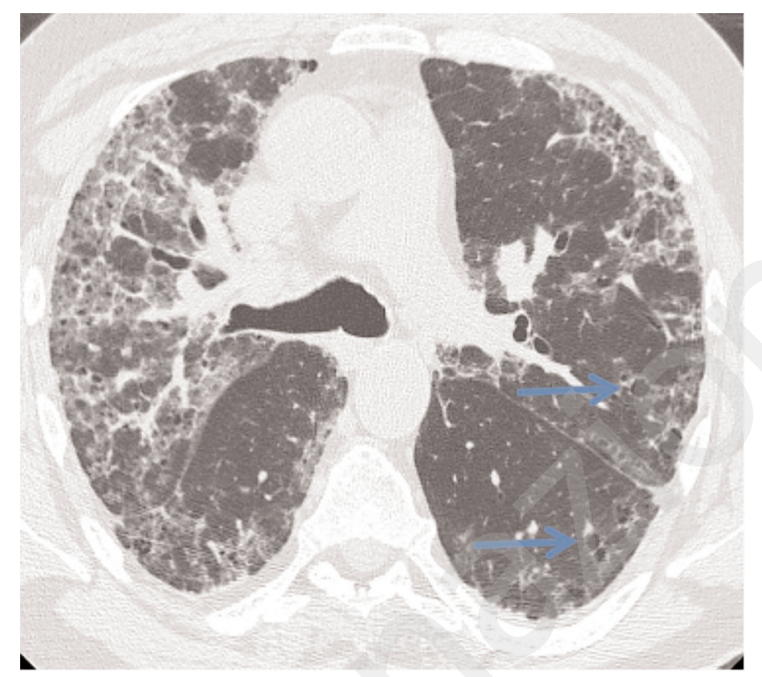

Figure 3 - LIP. High-resolution CT (HRCT) scan obtained at level of tracheal carina shows thin-walled cystic air spaces (arrows), areas of ground-glass attenuation and randomly distributed centrilobular nodules.

It is most commonly caused by thermophilic actinomycetes present in moldy hay and contaminated humidifiers or air conditioners, or proteins contained in birds' serum, droppings and feathers.

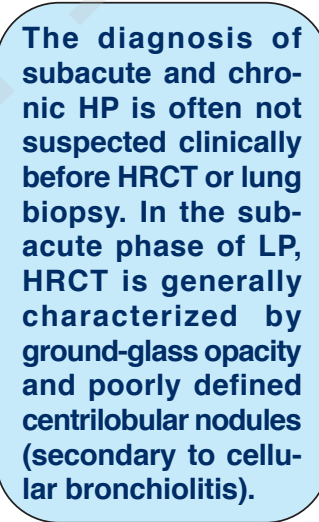

The diagnosis of subacute and chronic HP is often not suspected clinically before HRCT or lung biopsy. In the subacute phase of LP, HRCT is generally characterized by ground-glass opacity and poorly defined centrilobular nodules lar bronchiolitis).

The most common histologic features of HP are cellular bronchiolitis and peribronchiolar interstitial alveolitis due to bronchocentric lymphocytic infiltration and poorly defined non-necrotizing granulomas (16).

Clinically, HP can assume acute, subacute or chronic forms, which correspond to varying $C T$ patterns.

Heavy exposure to the inciting antigen may lead to the acute form of HP, characterized by dyspnea and fever developing within 4 to 8 hours after exposure and resolving within a few days, and identification of serum precipitins.

In subacute HP the presentation is more insidious, due to repeated exposures to relatively low doses of antigen leading to slowly progressive dyspnea over several weeks or months.

Chronic HP is caused by continued, low-level antigen exposure over months or years that may result in pulmonary fibrosis.

The diagnosis of subacute and chronic HP is often not suspected clinically before HRCT or lung biopsy.

In the subacute phase of HP, HRCT is generally characterized by groundglass opacity and poorly de-
Coexisting areas of decreased attenuation due to constrictive bronchiolitis may lead to the so called "head-cheese pattern". 
fined centrilobular nodules (secondary to cellular bronchiolitis) (17). Coexisting areas of decreased attenuation due to constrictive bronchiolitis may lead to the so called "head-cheese pattern".

The centrilobular nodules are typically poorly defined, measure less than $5 \mathrm{~mm}$ in diameter and have a prevalent middle and lower lung zones distribution; in some patients, centrilobular nodules may be the only finding or the predominant abnormality seen in HP (18).

The mosaic perfusion areas in HP often have a lobular distribution and increase in size on CT expiratory scans.

Approximately $10 \%$ of patients with subacute HP have lung cysts, probably secondary to partial small-airway obstruction by the bronchiolitis. Cysts are randomly distributed, thin-walled, ranging from 3 to $25 \mathrm{~mm}$ in maximal diameter and 1 to 15 in number (19).

For a radiological diagnosis of HP, the presence of cysts can be really helpful when they are found in association with the more classical signs of the disease, such as centrilobular nodules and mosaic attenuation pattern.

In chronic HP, fibrotic abnormalities can be found on HRCT. The fibrotic abnormalities may configure either a nonspecific interstitial pneumonia (NSIP) or a usual interstitial pneumonia (UIP) pattern $(20,21)$.

\section{DIP}

DIP is an uncommon disorder characterized histologically by macrophage accumulation filling the alveolar ducts and bronchiole, mild in-

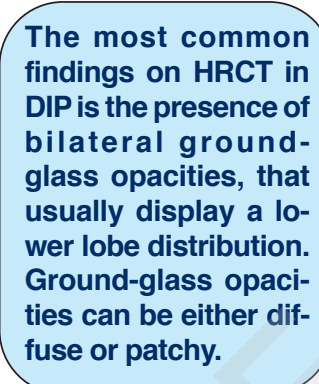

flammation of the alveolar walls and minimal fibrosis. DIP occurs most commonly in patients between 30 and 50 years of age, approximately $90 \%$ of which is current cigarette smokers; rarely, DIP can be associated with a variety of conditions in non-smokers, including drug reactions, asbestosis and human immunodeficiency virus (HIV) infection. It is more common in men than in women.
The clinical symptoms usually consist of progressive dyspnea and dry cough; the prognosis is good, improving with smoking cessation and corticosteroids therapy. The most common findings on HRCT in DIP is the presence of bilateral ground-glass opacities, that usually display a lower lobe distribution (22). Ground-glass opacities can be either diffuse or patchy.

In almost all of patients a fine reticular pattern due to intralobular linear thickening is seen, involving mainly the subpleural lung regions and lung bases.

Traction bronchiectasis and honeycombing are uncommon.

Small cysts have been reported in one third of patients with DIP (22). The cysts are usually round, thin-walled, and less than $2 \mathrm{~cm}$ in diameter (4).

Table 1 provides a ready-reference to the main cysts features in the most common pulmonary cystic disease.

\section{Rare causes of multiple lung cysts}

Although centrilobular emphysema, LAM, LCH, LIP, HP, DIP are the most frequently encountered causes of thin-walled cysts at HRCT, differential diagnosis of diffuse cystic lung disease is more extensive than previously described (23) (Table 2).

\section{Amyloidosis with cysts}

Pulmonary amyloidosis occurs as part of a systemic disease or a localized process restricted to the lung (primary pulmonary amyloidosis) with tracheobronchial, nodular parenchymal, diffuse parenchymal interstitial or diffuse alveolar septal distribution (24). Diffuse alveolar septal amyloidosis can rarely be associated with cysts formation (25). The mechanism of parenchymal cyst formation has been postulated to be In Amyloidosis with cysts, CT showed multiple cystic lesions of various size up to $1.5 \mathrm{~cm}$. The cysts were located mainly over the hilar and central zone, and high density areas were seen around the cysts.

the result either of airway narrowing by inflammation

Table 1 - Summary of HRCT features of cysts in pulmonary cystic disease.

\begin{tabular}{lllll}
\hline & Cysts Distribution & Cysts Shape & Cysts Wall & Cysts Size \\
\hline LAM & Diffuse & Regularly round & Thin & $\begin{array}{l}\text { Homogeneous, } \\
\text { generally small } \\
\text { (few millimeters) }\end{array}$ \\
\hline LCH & $\begin{array}{l}\text { Upper and middle lobes; spares } \\
\text { of the costophrenic recesses and } \\
\text { the medial tips of the middle lobe } \\
\text { and lingula }\end{array}$ & Bizarre & Thin and thick & $\begin{array}{l}\text { Varying in size } \\
\text { (ranging from } 10 \\
\text { mm to } 30 \mathrm{~mm} \text { ) }\end{array}$ \\
\hline LIP & Scattered & Round & From $1 \mathrm{~mm}$ to $30 \mathrm{~mm}$ \\
\hline HP & Scattered & Round & Thin & From $3 \mathrm{~mm}$ to $25 \mathrm{~mm}$ \\
\hline DIP & Upper or lower lobes & Round & Thin & Generally very small \\
\end{tabular}


Table 2 - Summary of HRCT features of rare diffuse cystic lung diseases.

\begin{tabular}{|c|c|c|}
\hline Diagnosis & Clinical Features and associations & Distinct HRCT Features \\
\hline Amyloidosis, LCDD & $\begin{array}{l}\text { Renal failure, Sjögren disease, } \\
\text { multiple myeloma, macroglobulinemia }\end{array}$ & Cysts and large nodules \\
\hline Birt-Hogg-Dubé syndrome & $\begin{array}{l}\text { Skin lesions, renal neoplasms, colonic } \\
\text { polyposis }\end{array}$ & Basilar subpleural lentiform cysts \\
\hline Neurofibromatosis & $\begin{array}{l}\text { Cutaneous and subcutaneous } \\
\text { neurofibromas, meningoceles, } \\
\text { kyphoscoliosis, ribbon deformity of the } \\
\text { ribs }\end{array}$ & $\begin{array}{l}\text { Cysts and ground-glass centrilobular } \\
\text { opacification with upper lobe } \\
\text { predominance }\end{array}$ \\
\hline Tracheobronchial papillomatosis & $\begin{array}{l}\text { Papillomas in the upper respiratory } \\
\text { tract }\end{array}$ & $\begin{array}{l}\text { Bilateral solid nodules and multiple } \\
\text { cysts in the posterior regions }\end{array}$ \\
\hline Cystic fibrohistiocytic tumor & $\begin{array}{l}\text { Fibrous histiocytomas of the skin, } \\
\text { pneumothorax }\end{array}$ & $\begin{array}{l}\text { Multiple bilateral pulmonary cysts, } \\
\text { nodules or masses }\end{array}$ \\
\hline Mesenchimal cystic hamartoma & Pneumothorax & $\begin{array}{l}\text { Pulmonary masses with multi- } \\
\text { lobulated cysts of varying size }\end{array}$ \\
\hline Pulmonary blastoma & Shortness of breath and chest pain & $\begin{array}{l}\text { Well-defined mixed solid and cystic } \\
\text { large mass }\end{array}$ \\
\hline Cystic metastases & History of malignancy & Peripheral or random distribution \\
\hline
\end{tabular}

and amyloid deposition (check valve mechanism) and increased fragility and rupture of alveolar walls due to amyloid deposition, or ischaemia resulting from amyloid deposition around capillaries. In the reported cases, CT showed multiple cystic lesions of various size up to $1.5 \mathrm{~cm}$. The cysts were located mainly over the hilar and central zone, and high density areas were seen around the cysts corresponding at histological

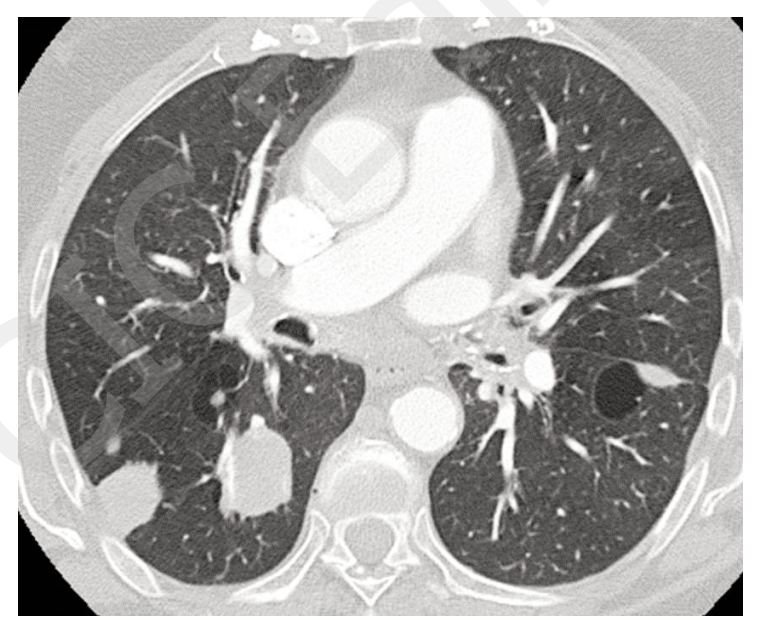

Figure 4 - AMYLOIDOSIS. A section CT passing under the tracheal carina shows multiple bilateral cysts of various sizes typically mainly located over the hilar and central zone. High density areas in the fissures and in the superior segment of the lower right lobe correspond to amyloid deposit at histological examination. examination to amyloid deposits (26) (Figure 4).

Some reported cases have shown both pulmonary lymphocytic infiltration and amyloid deposition, often in association with Sjögren's syndrome, raising the possibility that in this patients the cysts formation is related to the lymphocytic infiltration rather than the amyloid deposition, since cystic change is recognised to occur in lymphocytic interstitial pneumonia (LIP) $(27,28)$.

\section{Light-chain deposition disease (LCDD)}

Light-chain deposition disease (LCDD) occurs in middleaged patients $(75 \%$ of cases in association with multiple myeloma or macroglobulinemia) and commonly involves the kidneys. Although lung involvement is rare, LCDD can result in respiratory failure and require lung transplantation (29). The light chains are secreted by a plasma clone and deposit in the alveolar
HRCT manifestations of LCDD may include nodules, lymphadenopathy, and cysts. walls, small airways and vessels. HRCT manifestations most commonly include nodules, lymphadenopathy and cysts (23). Cysts formation presumably has similar pathogenesis of pulmonary amyloidosis and is believed to correspond to dilation of the small airways (24).

\section{Birt-Hogg-Dubé syndrome}

This syndrome is a rare autosomal dominant charac- 
In BHD the cysts are scattered, lentiform or oval, sometimes several $\mathrm{cm}$. large, thin-walled with lower-medial predominance in subpleural zone.

terized by the presence of cutaneous hamartomas (predominantly fibrofolliculomas) distributed over the face, neck and upper trunk, renal tumors (ranging from benign oncocytomas to renal cell carcinomas) and diffuse cystic lung disease. Patients may have isolated lung cysts without involvement of skin and/or kidney and frequently develop pneumothoraces. The majority of patients has identifiable mutations in the folliculin gene (FLCN, also known as BHD) that interestingly is also associated with dysregulation of mTOR signalling pathway in pulmonary LAM (30-33). HRCT findings in Birt-Hogg-Dubé syndrome show thin-walled cysts $(80 \%)$. Radiologically, the cysts are scattered, thinwalled with lower-medial predominance in subpleural zones (23). Typically, these cysts are often lentiform or oval and some of them may be large (i.e. measuring several centimeters) (34).

\section{Neurofibromatosis}

Neurofibromatosis has variable manifestations in the thorax and lungs including intrathoracic neurogenic tumors, meningoceles, kyphoscoliosis, ribbon deformity of the ribs, cutaneous and subcutaneous neurofibromas of the chest wall and interstitial lung disease (ILD) as distinct clinical entity, not associated to smoking (3538). Histological documented Iymphoplasmocytic inflammation of the alveolar septa in neurofibromatosis could lead to cyst formation by check valve mechanism

Typical findings on HRCT include cysts and ground-glass centrilobular opacifications with upper lobe predominance. Indeed the main differential radiological diagnosis is with LCH, LIP and HP.

but the exact aetiology is still uncertain. Typical findings on HRCT include cysts and ground-glass centrilobular opacifications with upper lobe predominance. Indeed the main differential radiological diagnosis is with LCH (39), LIP and HP (19, 40).

\section{Cystic lung tumors}

\section{Mesenchymal cystic pulmonary hamarto- mas and pulmonary blastomas are descri- bed as pulmonary masses with cysts. Usually the combina- tion of these nodules or masses suggests the cancerous aetio- logy of these cysts.}

Some primary lung tumors and lung metastases may display cystic abnormalities on CT. Some mesenchymal neoplasms with different degree of malignancy such as advanced tracheobronchial papillomatosis, cystic fibrohistiocytic tumor, mesenchymal cystic pulmonary hamartomas and pulmonary blastoma may be associated with a cystic pattern (41).

In advanced tracheobronchial papillomatosis and cystic fibrohistiocystic tumor cystic lesions are often multiple and bilateral $(42,43)$. Mesenchymal cystic pulmonary hamartomas and pulmonary blastomas are described as pulmonary masses with cysts. Usually, the combination of these nodules or masses suggests the cancerous aetiology of these cysts.

\section{Advanced tracheobronchial papillomatosis}

In less than $1 \%$ of cases tracheobronchial papillomatosis spreads into the lung parenchyma from larynx, trachea and mainstem bronchi, and appears on HRCT as characterized by bilateral solid nodules and multiple cysts (less numerous than in LAM or LCH) with thin or thick walls. These cysts are typically localized in the posterior regions $(4,42,44)$.

\section{Cystic fibrohistiocytic tumor}

This tumor is extremely rare and represents in most cases a metastatic localization from a benign or lowgrade cellular fibrous histiocytomas of the skin, though occasionally may be primary. On HRCT, it usually occurs as multiple bilateral pulmonary cysts that represent a sort of cystic changes of multiple pulmonary nodules or masses. Pneumothorax is a frequent associated feature $(45,46)$.

\section{Mesenchimal cystic hamartoma of the lung}

Mesenchymal cystic pulmonary hamartoma is a rare subtype of pulmonary hamartoma that can occur in adults and children. On CT it usually manifests as pulmonary masses with multilobulated cysts of varying size. The lesions may be multiple and bilateral and cause frequently pneumothorax. The differential diagnosis should include atypical cystic chest masses such as cystic adenomatoid
Cystic adenomatoid malformation, lung cystic fibrohistiocytic tumor and pulmonary blastoma should be suspected in presence of atypical cystic chest masses. malformation, lung cystic fibrohistiocytic tumor and pulmonary blastoma $(47,48)$.

\section{Pulmonary blastoma}

Pulmonary blastomas are a rare group of primary lung tumors $(0.25-0.5 \%$ of lung malignancy) that are composed of immature malignant epithelial and/or mesenchymal tissues resembling early embryological lung tissues in histological specimen. On CT, pulmonary blastoma is usually described as well-defined mixed solid and cystic large mass measuring $1.5 \mathrm{~cm}$ to $13 \mathrm{~cm}$ with variable contrast enhancement and necrotic cen- 
tre, which may completely opacify the hemithorax and cause mediastinal shift. Pleural effusion is a less frequent associated feature, though atypical cases of pul-

On CT, pulmonary blastoma is usually described as well-defined mixed solid and cystic large mass measuring $1.5 \mathrm{~cm}$ to 13 with variable contrast enhancement and necrotic centre which may completely opacify the hemithorax and cause mediastinal shift. monary blastoma manifesting as recurrent pleural effusions in the absence of a detectable lung mass were reported (49-51). Childhood pulmonary blastomas are considered different entities from adult pulmonary blastomas and may occur in combination with pre-existing benign cysts (either cystic adenomatoid malformations or bronchogenic cysts of the lung). In children the tumor mass may completely opacify the hemithorax and cause mediastinal shift $(52,53)$.

\section{Cystic pulmonary metastases}

Cystic pulmonary metastases occur most frequently in tumors of epithelial origin (oropharyngeal squamous cell cancer, pancreatic adenocarcinoma, transitional cell carcinoma of the bladder) and less frequently in tumors of mesenchymal origin and lymphoma (54). Mesenchymal neoplasms in which pulmonary cysts have been reported include benign mestastasing leiomyoma (55), leiomyosarcoma (54), synovial cell sarcoma (54), epithelioid cell sarcoma (56) and endometrial stromal sarcoma (ESS) (57). Immunostains are useful in distinguishing metastatic ESS from

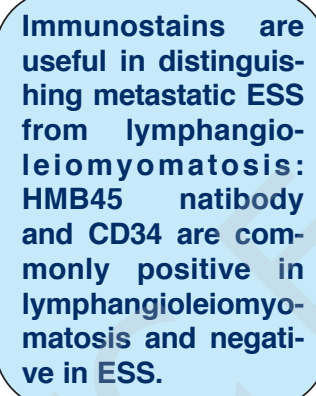
HMB45 antibody and CD34 are commonly positive in lymphangioleiomyomatosis and negative in ESS (57). On chest CT as with other metastatic lesions, cystic metastases tend to have different sizes, various shapes and a basilar predominance $(42,43)$.

\section{References}

1. Lenoir S, Grenier P, Brauner MW, Frija J, Remy-Jardin M, Revel D, Cordier JF. Pulmonary lymphangiomyomatosis and tuberous sclerosis: comparison of radiographic and thin-section CT findings. Radiology 1990;175:329-34.

2. Chorianopoulos D, Stratakos G. Lymphangioleiomyomatosis and tuberous sclerosis complex. Lung 2008;186:197-207.

3. Johnson SR, Tattersfield AE. Clinical experience of lymphangioleiomyomatosis in the UK. Thorax 2000;55:1052-7.

4. Koyama M, Johkoh T, Honda O, Tsubamoto M, Kozu- ka T, Tomiyama N, Hamada S, Nakamura H, Akira M, Ichikado K, Fujimoto K, Rikimaru T, Tateishi U, Müller NL. Chronic cystic lung disease: diagnostic accuracy of high-resolution CT in 92 patients. AJR Am J Roentgenol 2003;180:827-35.

5. Lee KH, Lee JS, Lynch DA, Song KS, Lim TH. The radiologic differential diagnosis of diffuse lung diseases characterized by multiple cysts or cavities. J Comput Assist Tomogr 2002; 26:5-12.

6. Abbott GF, Rosado-de-Christenson ML, Franks TJ, Frazier AA, Galvin JR. From the archives of the AFIP: pulmonary Langerhans cell histiocytosis. Radiographics 2004;24:821-41.

7. Torre O, Harari S. The diagnosis of cystic lung diseases: a role for bronchoalveolar lavage and transbronchial biopsy? Respir Med 2010;104.

8. Nicholson AG. Lymphocytic interstitial pneumonia and other lymphoproliferative disorders in the lung. Semin Respir Crit Care Med 2001;22:409-22.

9. Cha SI, Fessler MB, Cool CD, Schwarz MI, Brown KK. Lymphoid interstitial pneumonia: clinical features, associations and prognosis. Eur Respir J 2006;28: 364-9.

10. American Thoracic Society; European Respiratory Society. American Thoracic Society/European Respiratory Society International Multidisciplinary Consensus Classification of the Idiopathic Interstitial Pneumonias. Am J Respir Crit Care Med 2002;165:277304.

11. Silva Cl, Flint JD, Levy RD, Müller NL. Diffuse lung cysts in lymphoid interstitial pneumonia: high-resolution CT and pathologic findings. J Thorac Imaging 2006;21:241-4.

12. Johkoh T, Ichikado K, Akira M, Honda O, Tomiyama N, Mihara N, Kozuka T, Koyama M, Hamada S, Nakamura H. Lymphocytic interstitial pneumonia: follow-up CT findings in 14 patients. J Thorac Imaging 2000; 15:162-7.

13. Park KH, Kwon SS, Chung MH, Kim J, Lee HJ, Min JW, Kim YH. A Case of Pulmonary MALT Lymphoma Arising from Lymphocytic Interstitial Pneumonitis. Tuberc Respir Dis (Seoul) 2012;73:115-21.

14. Watanabe $Y$, Koyama S, Miwa C, Okuda S, Kanai Y, Tetsuka K, Nokubi M, Dobashi Y, Kawabata Y, Kanda Y, Endo S. Pulmonary mucosa-associated lymphoid tissue (MALT) lymphoma in Sjögren's syndrome showing only the LIP pattern radiologically. Intern Med 2012;51:491-5.

15. Johkoh T, Müller NL, Pickford HA, Hartman TE, Ichikado K, Akira M, Honda O, Nakamura H. Lymphocytic interstitial pneumonia: thin-section CT findings in 22 patients. Radiology 1999;212:567-72.

16. Grunes D, Beasley MB. Hypersensitivity pneumonitis: a review and update of histologic findings. J Clin Pathol 2013;66:888-95.

17. Silver SF, Müller NL, Miller RR, Lefcoe MS. Hypersensitivity pneumonitis: evaluation with $\mathrm{CT}$. Radiology 1989;173:441-5.

18. Buschman DL, Gamsu G, Waldron JA Jr, Klein JS, King TE Jr. Chronic hypersensitivity pneumonitis: use of CT in diagnosis. AJR Am J Roentgenol 1992; 159:957-60. 
19. Franquet T, Hansell DM, Senbanjo T, Remy-Jardin M, Müller NL. Lung cysts in subacute hypersensitivity pneumonitis. J Comput Assist Tomogr 2003;27:4758.

20. Sahin H, Brown KK, Curran-Everett D, Hale V, Cool CD, Vourlekis JS, Lynch DA. Chronic hypersensitivity pneumonitis: CT features comparison with pathologic evidence of fibrosis and survival. Radiology 2007;244:591-8.

21. Silva $\mathrm{Cl}$, Müller NL, Lynch DA, Curran-Everett $D$, Brown KK, Lee KS, Chung MP, Churg A. Chronic hypersensitivity pneumonitis: differentiation from idiopathic pulmonary fibrosis and nonspecific interstitial pneumonia by using thin-section CT. Radiology 2008;246:288-97.

22. Hartman TE, Primack SL, Swensen SJ, Hansell D, McGuinness G, Müller NL. Desquamative interstitial pneumonia: thin-section CT findings in 22 patients. Radiology 1993;187:787-90.

23. Seaman DM, Meyer CA, Gilman MD, McCormack FX. Diffuse cystic lung disease at high-resolution CT. AJR Am J Roentgenol 2011;196:1305-11.

24. Clarke BE. Cystic lung disease. J Clin Pathol 2013 Oct;66:904-908.

25. Ohdama S, Akagawa S, Matsubara O, Yoshizawa Y. Primary diffuse alveolar septal amyloidosis with multiple cysts and calcification. Eur Respir J 1996;9:156971.

26. Desai SR, Nicholson AG, Stewart S, Twentyman OM, Flower CD, Hansell DM. Benign pulmonary lymphocytic infiltration and amyloidosis: computed tomographic and pathologic features in three cases. J Thoracic Imaging 1997;12:215-20.

27. Baqir M, Kluka EM, Aubry M-C, Hartman TE, Yi ES, Bauer PR, Ryu JH. Amyloid-associated cystic lung disease in primary Sjögren's syndrome. Respir Med 2013;107:616-21.

28. Jeong YJ, Lee KS, Chung MP, Han J, Chung MJ, Kim $\mathrm{KI}$, Seo JB, Franquet T. Amyloidosis and lymphoproliferative disease in Sjögren syndrome: thin-section computed tomography findings and histopathologic comparisons. J Comput Assist Tomogr 2004;28:776-81.

29. Colombat M, Stern M, Groussard O, Droz D, Brauner M, Valeyre D, Mal H, Taillé C, Monnet I, Fournier M, Herson S, Danel C. Pulmonary cystic disorder related to light chain deposition disease. Am J Respir Crit Care Med 2006;173:777-780.

30. Furuya M, Tanaka R, Koga S, Yatabe Y, Gotoda H, Takagi S, Hsu YH, Fujii T, Okada A, Kuroda N, Moritani S, Mizuno H, Nagashima Y, Nagahama K, Hiroshima K, Yoshino I, Nomura F, Aoki I, Nakatani Y. Pulmonary cysts of Birt-Hogg-Dubé syndrome: a clinicopathologic and immunohistochemical study of 9 families. Am J Surg Pathol 2012;36:589-600.

31. Koga S, Furuya M, Takahashi Y, Tanaka R, Yamaguchi A, Yasufuku K, Hiroshima K, Kurihara M, Yoshino I, Aoki I, Nakatani Y. Lung cysts in Birt-Hogg-Dubé syndrome: histological characteristics and aberrant sequence repeats. Pathol Int 2009;59:720-8.

32. Toro JR, Pautler SE, Stewart L, Glenn GM, Weinreich M, Toure O, Wei MH, Schmidt LS, Davis L, Zbar B, Choyke P, Steinberg SM, Nguyen DM, Linehan WM.
Lung cysts, spontaneous pneumothorax and genetic associations in 89 families with Birt-Hogg-Dubé syndrome. Am J Respir Crit Care Med 2007;175:1044-53.

33. Furuya M, Nakatani Y. Birt-Hogg-Dubé syndrome: clinicopathological features of the lung. J Clin Pathol 2013;66:178-86.

34. Tobino K, Gunji Y, Kurihara M, Kunogi M, Koike K, Tomiyama N, Johkoh T, Kodama Y, Iwakami S, Kikkawa M, Takahashi K, Seyama K. Characteristics of pulmonary cysts in Birt-Hogg-Dubé syndrome: thin-section CT findings of the chest in 12 patients. Eur J Radiol 2009 Sep 24.

35. Zamora AC, Collard HR, Wolters PJ, Webb WR, King TE. Neurofibromatosis-associated lung disease: a case series and literature review. Eur Respir J 2007; 29:210-4.

36. Ryu JH, Parambil JG, McGrann PS, Aughenbaugh GL. Lack of evidence for an association between neurofibromatosis and pulmonary fibrosis. Chest 2005;128:2381-6.

37. Oikonomou A, Vadikolias K, Birbilis T, Bouros D, Prassopoulos P. HRCT findings in the lungs of non-smokers with neurofibromatosis. Eur J Radiol. 2011;80: 520-3.

38. Shino MY, Rabbani S, Belperio JA, Lynch JP 3rd, Weigt SS. Neurofibromatosis-associated diffuse lung disease: case report. Semin Respir Crit Care Med 2012;33:572-575.

39. Hidalgo A, Franquet T, Giménez A, Bordes R, Pineda $R$, Madrid M. Smoking-related interstitial lung diseases: radiologic-pathologic correlation. Eur Radiol 2006;16:2463-70.

40. Ichikawa Y, Kinoshita M, Koga T, Oizumi K, Fujimoto $\mathrm{K}$, Hayabuchi N. Lung cyst formation in lymphocytic interstitial pneumonia: CT features. Comput Assist Tomogr 1994;18:745-8.

41. Grant LA, Babar J, Griffin N. Cysts, cavities, and honeycombing in multisystem disorders: differential diagnosis and findings on thin-section CT. Clin Radiol 2009;64:439-448.

42. Cantin L, Bankier AA, Eisenberg RL. Multiple cystlike lung lesions in the adult. AJR 2010;194:W1-W11.

43. Ryu JH, Swensen SJ. Cystic and cavitary lung diseases: focal and diffuse. Mayo Clin Proc 2003;78: 744-752.

44. Raman SP, Pipavath SN, Raghu G, Schmidt RA, Godwin JD. Imaging of thoracic lymphatic diseases. AJR Am J Roentgenol 2009;193:1504-1513.

45. Gu M, Sohn K, Kim D, Kim B. Metastatizing dermatofibroma in the lung. Ann Diagn Pathol 2007;11:64-673.

46. Osborn M, Mandys V, Beddow E, Ladas G, Florio R, Sheppard MN, Fisher C, Bell SW, Travis WD, Nicholson AG. Cystic fibrohistiocytic tumours presenting in the lung: primary or metastatic disease? Histopathology 2003;43:556-62.

47. Souza FF, Chen E. Mesenchymal cystic hamartoma of the lung: MRI and PET/CT appearance. J Thorac Imaging 2009;24:52-5.

48. Meza MP, Newman B, Dickman PS, Towbin RB. Pediatric case of the day. Pulmonary mesenchymal cystic hamartoma. Radiographics 1992;12:843-844.

49. Walker RI, Suvarna K, Matthews S. Case report: pul- 
monary blastoma: presentation of two atypical cases and review of the literature. Br J Radiol 2005;78:437440.

50. Wang J, Sun H, Bai R, Liu H anf Yu T. Pulmonary Blastoma with Endobronchial Growth. J Thorac Oncol 2009;4:543-544.

51. Lee HJ, Goo JM, Kim KW, Im JG, Kim JH. Pulmonary blastoma: radiologic findings in five patients. Clin Imaging 2004;28:113-118.

52. Dehner LP. Pleuropulmonary blastoma is the pulmonary blastoma of childhood. Semin Diagn Pathol 1994;11:144-151.

53. Senac MO, Wood BP, Isaacs $\mathrm{H}$, Weller M. Pulmonary blastoma: a rare childhood malignancy. Radiology 1991;179:743-746.
54. Traweek T, Rotter AJ, Swartz W, Azumi N. Cystic pulmonary metastatic sarcoma. Cancer 1990;65: 1805-1811.

55. Aboualfa K, Calandriello L, Dusmet M, Ladas G, Hansell DM, Nicholson AG. Benign metastasizing leiomyoma presenting as cystic lung disease: a diagnostic pitfall. Histopathology 2011;59:796-9.

56. Chan DP, Griffith JF, Lee TW, Chow LT, Yim AP. Cystic pulmonary metastases from epithelioid cell sarcoma. Ann Thorac Surg 2003;75:1652-16.

57. Aubry MC, Myers JL, Colby TV, Leslie KO, Tazelaar HD. Endometrial stromal sarcoma metastatic to the lung: a detailed analysis of 16 patients. Am J Surg Pathol 2002;26:440-44. 